
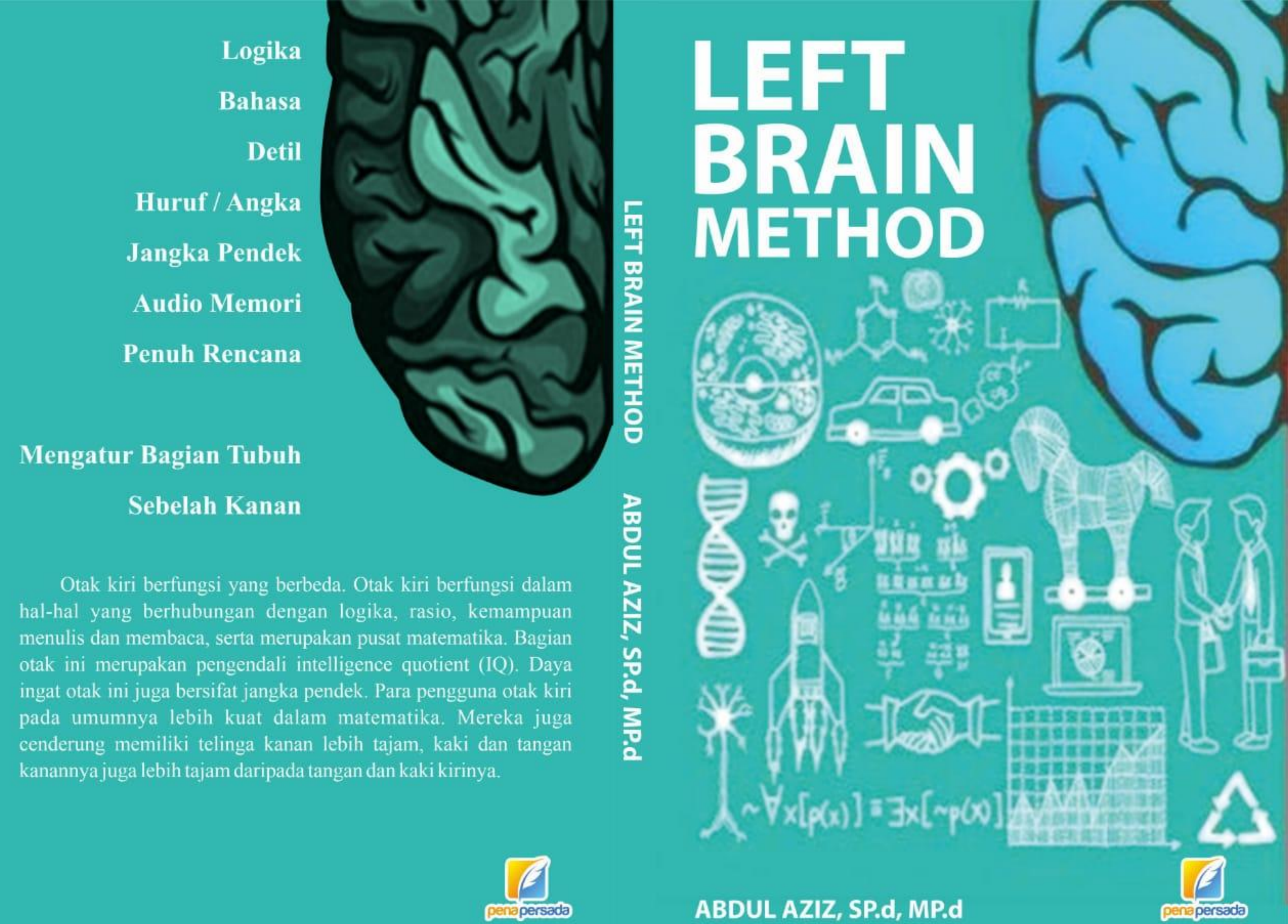

ABDUL AZIZ, SP.d, MP.d

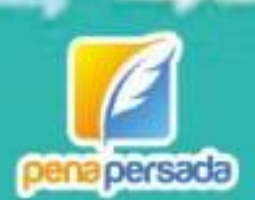




\section{LIFT BRAIN METHOD}

Abdul Aziz, SP.d,. MP.d.

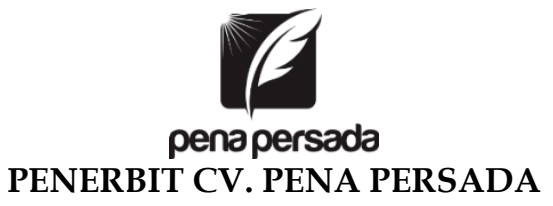




\title{
LIFT BRAIN METHOD
}

\author{
Penulis : \\ Abdul Aziz, SP.d,. MP.d. \\ ISBN : 978-623-6688-96-0 \\ Cover Design: \\ Retnani Nur Briliant \\ Layout : \\ Nisa Falahia

\section{Penerbit CV. Pena Persada} \\ Redaksi : \\ Jawa Tengah \\ Email : penerbit.penapersada@gmail.com \\ Website : penapersada.com \\ Phone : (0281) 7771388
}

Jl. Gerilya No. 292 Purwokerto Selatan, Kab. Banyumas

\section{Anggota IKAPI}

All right reserved

Cetakan pertama : 2020

Hak Cipta dilindungi oleh undang-undang. Dilarang memperbanyak karya tulis ini dalam bentuk apapun tanpa izin penerbit. 


\section{KATA PENGANTAR}

Dengan memanjatkan puji dan syukur kehadirat Allah SWT, maka buku panduan Metode Otak Kiri terselesaikan dengan baik. Buku ini disusun untuk memberikan pengetahuan pembelajaran metode otak kiri..

Metode Otak kiri bekerja dengan menggunakan dengan menggunakan daya ingat yang memiliki sifat jangka pendek (short term memory) sehingga akan berpengaruh pada fungsi berbicara, berbahasa, serta matematika. Jutaan sel sel di dalam otak kiri ini mampu memproses informasi yang memiliki sifat logis, lineal, serta rasional.

Saya menyampaikan terima kasih kepada seluruh pihak yang telah membantu terbitnya buku ini, khususnya tim penyusun. Semoga upaya yang telah dicurahkan bermanfaat bagi pembaca di Indonesia, khususnyapara pendidik untuk menerapkan metode otak kanan dalam pembelajaran terbuka. Untuk kritik dan saran dari teman sejawat sekalian, guna perbaikan penyusunan buku ini ke depan.

Dengan adanya buku ini bisa diterapkan para pendidik untuk menerapkan metode otak kiri dalam pembelajaran terbuka. Untuk kritik dan saran dari teman sejawat sekalian, guna perbaikan penyusunan buku ini ke depan. 


\section{DAFTAR ISI}

KATA PENGANTAR ………………………….................... i

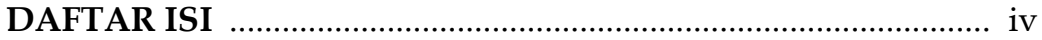

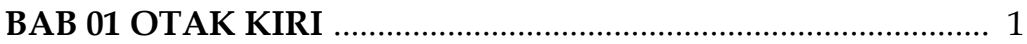

A. Pengertian Otak Kiri ........................................................... 1

B. Struktur Otak Kiri.................................................................. 1

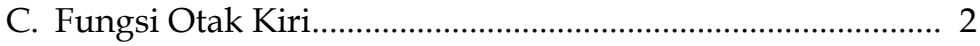

D. Pengontrolan ……............................................................. 2

E. Keterampilan Angka-Angka ............................................. 2

F. Sebagai Pengambil Tindakan yang Mengandalkan

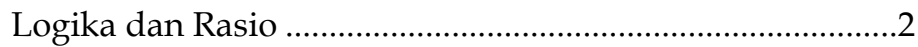

G. Pusat Inteligent Quotient (IQ) ..................................................

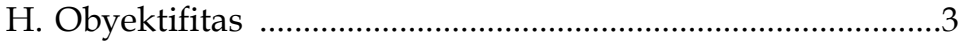

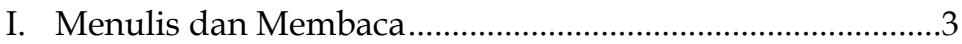

J. Cara Kerja Otak Kiri ...........................................................

BAB 02 BERPIKIR DENGAN OTAK KIRI ..................................

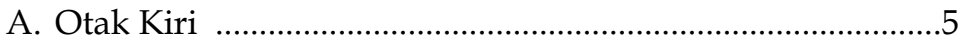

B. Belajar dengan Menggunakan Angka ...................................5

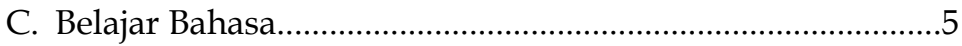

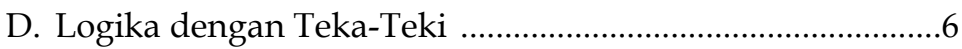

E. Membedakan Berfikir dengan Otak Kanan dan Kiri ...........6

BAB 03 YUK PAHAMI CARA KERJA OTAK KIRI DAN OTAK KANAN AGAR BELAJAR MAKIN MAKSIMAL ........9

A. Cara Kerja Otak Kiri dan Otak Kanan ................................ 9

B. Penemuan Roger W. Sperry ...............................................

C. Seseorang yang Dominan Belahan Kiri, Biasan Akan

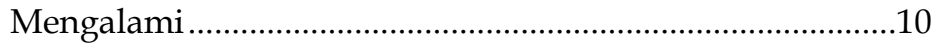

D. Salah Persepsi Antara Kinerja Otak Kanan dan Otak

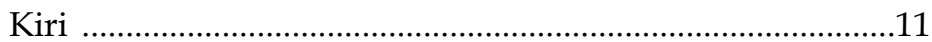

E. Otak Kita yang Tidak Seimbang (Asimetris) ........................12

F. Tentang Otak Kiri .............................................................13

BAB 046 CARA MELATIH DAN MENGOPTIMALKAN OTAK KANAN DAN KIRI ANAK ……………….................15

A. Cara Melatih Otak Kiri dan Otak Kanan Anak ....................15 
BAB 05 PERBEDAAN FUNGSI OTAK KIRI DAN OTAK

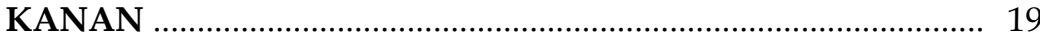

A. Perbedaan Fungsi Otak Kiri dan Otak Kanan ................... 19

B. Otak Kiri........................................................................ 20

C. Otak Kanan ............................................................................. 20

D. Perbedaan Otak Kanan dan Otak Kiri .............................. 21

BAB 06 PSIKOLOGI OTAK .................................................. 22

A. Yakin Otak Kiri Lebih Dominan atau Sebaliknya ............. 22

B. Otak Kiri Logika, Otak Kanan Seni .................................. 22

C. Teorinya Dipatahkan ......................................................... 23

D. Dua Lebih Baik dari Satu .................................................. 23

BAB 07 OTAK KIRI LEBIH DOMINAN, BENARKAH ORANG ITU LEBIH CERDAS .............................................. 25

A. Dominan Otak Kiri ............................................................ 25

B. Otak Kanan dan Otak Kiri,Manakah yang Lebih Baik .... 26

C. Otak Kiri VS Otak Kanan .................................................... 26

D. Ciri-Ciri Orang dengan Dominan Otak Kanan ................. 27

E. Ciri-Ciri Orang dengan Dominan Otak Kiri .................... 27

BAB 08 OTAK KANAN DAN OTAK KIRI, MANAKAH YANG LEBIH BAIK ................................................................ 28

A. Otak Manusia ....................................................................... 28

B. Otak Kiri VS Otak Kanan ................................................ 28

C. Ciri-Ciri Orang dengan Dominan Otak Kanan ................. 29

D. Ciri-Ciri Orang dengan Dominan Otak Kiri ..................... 29

BAB 09 INI PENTINGNYA KESEIMBANGAN OTAK KIRI DAN OTAK KANAN ................................................... 31

A. Menyeimbangkan Otak Kiri dan Otak Kanan .................. 31

B. Kreativitas, Aktivitas, dan Pelayanan .............................. 32

BAB 10 BEGINI ORANG BERKPRIBADIAN OTAK KIRI DAN OTAK KANAN APA SAJA BEDANYA ............... 35

A. Orang Kepribadian Otak Kiri dan Otak Kanan ................ 35

B. Kepercayaan Otak Kiri Vs Otak Kanan .............................. 35

C. Orang-Orang Berotak Kiri dikatakan Lebih Banyak.......... 35

D. Orang-Orang Berotak Kanan dikatakan Lebih Banyak ..... 36

E. Penelitian Otak Kiri Vs Otak Kanan................................... 36

F. Fungsi dan Karakteristik Masing-Masing Belahan Otak ... 36 
BAB 11 MENYEIMBANGKAN OTAK KIRI DAN KANAN

DENGAN BERKESENIAN ................................................... 39

A. Menyeimbangkan Otak dengan Kesenian ........................... 39

BAB 12 OTAK KIRI LEBIH DOMINAN, BENARKAH ORANG ITU LEBIH CERDAS .................................................. 41

A. Anak Dominan Otak Kiri Termasuk Orang Cerdas ........... 41

BAB 1331CARA KREATIF BAGI KAMU YANG MENGANDALKAN OTAK KIRI ........................................ 43

A. Kreativitas dengan Otak Kiri ................................................ 43

BAB 146 CARA MELATIH OTAK KIRI AGAR TIDAK

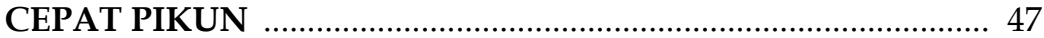

A. Melatih Otak Kiri agar Tidak Pikun........................................ 47

BAB 15 POTENSI KINERJA OTAK KIRI .................................... 50

A. Potensi Kinerja Otak Kiri ………………….......................... 50

B. Fungsi Otak Kiri ................................................................. 50

BAB 16 FUNGSI DAN CARA MENGAKTIFKAN OTAK

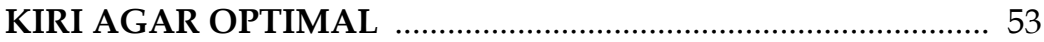

A. Fungsi Otak Kiri .................................................................... 53

B. Tips dan Cara Mengaktifkan Otak Kiri ………………….... 53

C. Karakter dari Otak Kiri .......................................................... 54

D. Makanan yang Baik untuk Mengembangkan Otak............. 54

BAB 17 APLIKASI METODE OTAK UNGGUL MAMPU OPTIMALKAN KEMAMPUAN BERFIKIR UMUM ................. 56

A. Aplikasi Metode Pengembangan KemampuanOtak ........... 56

BAB 18 APAKAH ANAK ANDA DOMINAN OTAK

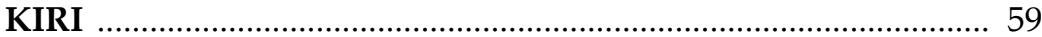

A. Anak Dominan Otak Kiri .................................................... 59

B. Inilah Cara-cara Memaksimalkan Fungsi Otak Anak yang Dominan Otak Kiri 59

BAB 1923 TIPS AMPUH MELATIH DAN MENGOPTIMAL-

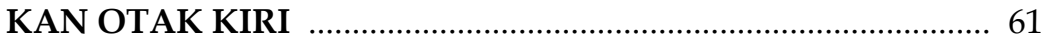

A. Melatih Otak Kiri ................................................................ 61

BAB 20 MENGOPTIMALKAN KERJA OTAK KIRI DAN

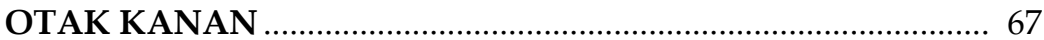

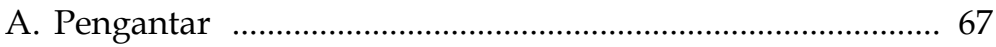

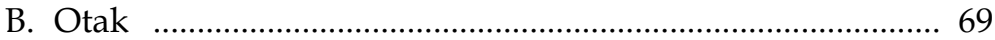

C. Karakteristik Otak Kiri ......................................................... 71 
D. Fungsi Otak Kiri ………………........................................ 71

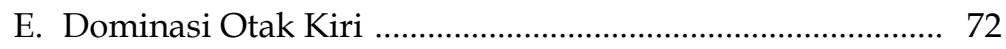

F. Teknik Menyeimbangkan Otak Kiri dan Otak Kanan ....... 73

G. Menggunakan Musik ........................................................ 74

H. Membiasakan Berolahraga ............................................. 74

I. Multi Stimulus Hasilkan Pengalaman Belajar Efektif ........ 75

J. Quantum Learning.............................................................. 76

K. Cara Merancang Pembelajaran dengan Mengoptimalkan Kerja Otak Kiri dan Kanan ................................................. 79

BAB 21 LEBIH BAIK MANA, ASAH OTAK KANAN ATAU

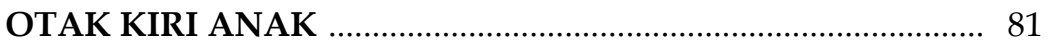

A. Mengasah Otak Kiri dan Otak Kanan Anak ...................... 81 BAB 22 CARA MELATIH OTAK KIRI DAN OTAK KANAN AGAR PINTAR MAKSIMAL ................................................... 83

A. Melatih Otak Kiri dan Otak Kanan ...................................... 83

B. Apakah Otak Kanan Lebih Baik daripada Otak Kanan .... 83

C. Hampir Setiap Waktu, Kedua Belahan Otak Kita Aktif .... 85

D. Gunakan Semaksimal Mungkin Kedua Belah Otak

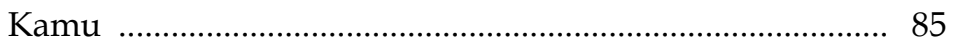

E. Latihan Otak Kiri dan Otak Kanan ..................................... 86

BAB 23 CARA MELATIH OTAK KIRI AGAR PINTAR

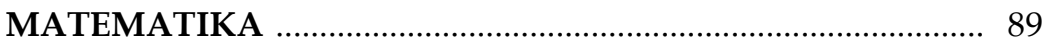

A. Otak Manusia .................................................................... 89

\section{BAB 244 AKTIVITAS UNTUK MANGASAH OTAK} KANAN DAN KIRI ANAK .................................................... 91

A. Aktivitas Otak Kanan dan Kiri Anak .................................... 91

B. Otak dan Kreativitas ........................................................... 91

C. Otak Kanan dan Kiri Anak ..................................................... 91

D. Mendorong Perkembangan Semua Bagian Otak .............. 92

E. Berpikir dengan Otak Kanan ........................................... 92

F. Aktivitas Berikut Mendorong Stimulasi Otak Kanan ........ 93

G. Berpkir dengan Otak Kiri ................................................... 93

H. Lakukan Hal Berikut Untuk Menstimulasi Otak Kiri

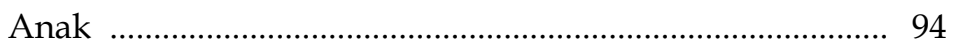

I. Apakah Anak Anda Cenderung Otak Kanan .................... 94 
J. Aktivitas untuk Meningkatkan Kemampuan Otak Kanan dan Kiri Anak

BAB 25 MAKSIMALKAN PERANAN OTAK KIRI DAN OTAK KANAN DALAM BELAJAR SUPAYA LEBIH EFEKTIF 101

A. Memaksimalkan Otak Kiri dan Otak Kanan 101

BAB 268 FAKTA ILMIAH MUSIK BISA MENGOBATI

A. Musik Bisa Mengobati Patah Hati ........................................ 103

B. Mendenagrkan Musik Klasik ................................................ 103

BAB 27 CARA MELATIH OTAK KIRI ...................................... 104

A. Ada Beberapa yang Perlu Kalian Harus TauTentang Melatih Otak Kiri ................................................................. 104

B. Cara Mengoptimalkan Otak Kiri dan Kanan Anak .............. 105 BAB 28 KENALI CIRI-CIRI ANAK YANG DOMINAN

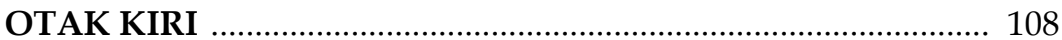

A. Kenali Ciri-Ciri Anak yang di Dominan Otak Kiri ............. 108

B. Otak Kiri dan Otak Kanan .................................................. 109

BAB 29 GAYA BELAJAR OTAK KIRI DAN OTAK

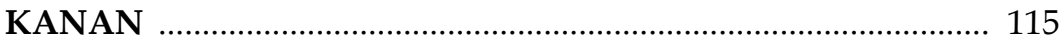

A. Tipe Belajar Otak kiri dan Otak Kanan .................................. 115

\section{BAB 30 BAGAIMANA MENGASAH OTAK KIRI DAN}

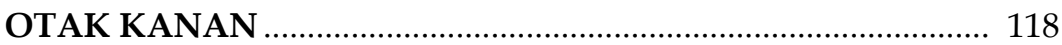

A. Mengasah Kemampuan Otak Kiri dan Otak Kanan ........... 118

B. Apakah Peran Masing-Masing Otak Berbeda ...................... 118

C. Tips Untuk Anda yang Memiliki Otak yang Lebih Dominan Sebelah Kanan ..................................................... 119

D. 4 Tips Untuk Anda yang Memiliki Otak yang Lebih Dominan Sebelah Kiri 120

BAB 31 INILAH PEKERJAAN YANG COCOK UNTUK KAMU YANG MENGGUNAKAN OTAK KIRI 123

A. Pekerjaan yang Cocok Dominan Otak Kiri ......................... 123 BAB 32 PEKERJAAN/PROFESI SESUAI DENGAN OTAK KIRI 125

A. Profesi Sesuai dengan Otak Kiri 125 
BAB 337 JENIS PERMAINAN ASAH OTAK KANAN

DAN KIRI ANAK

A. Jenis Permainan Otak Kanan dan Otak Kiri

BAB 34 BAGAIMANA PERAN OTAK KIRI DAN OTAK KANAN MANUSIA

A. Peran Otak Kiri dan Otak Kanan

B. Bagaimana Menyeimbangkan Kerja Otak Kiri danOtak Kanan

\section{BAB 35 KAITAN FUNGSI OTAK DENGAN} PERKEMBANGAN BAHASA

A. Fungsi Otak dengan Perkembangan Bahasa 134

BAB 36 TAHAP-TAHAP PERKEMBANGAN OTAK

BAHASA PADA ANAK 138

A. Perkembangan Bahasa Otak Pada Anak 138

BAB 37 KAITAN FUNGSI OTAK KIRI

DENGAN PERKEMBANGAN BAHASA 141

A. Fungsi Otak Kiri dengan Perkembangan Bahasa 141

BAB 38 KINERJA DAN KARAKTERISTIK OTAK KIRI 145

A. Pengertian Kinerja Otak Kiri 145

B. Kinerja Otak Kiri 145

C. Karakteristik Otak Kiri 149

BAB 39 PENUTUP 151

DAFTAR PUSTAKA 153 


\section{LIFT BRAIN METHOD}




\section{BAB 01 OTAK KIRI}

\section{A. Pengertian Otak Kiri}

Otak kiri ini merupakan bagian dari otak besar (cerebrum) yang berada pada posisi sebelah kiri. Otak kiri juga merupakan salah satu organ terpenting pada bagian tubuh yang memiliki peran dalam mengontrol seluruh pusat dari sistem syaraf serta juga struktur sel saraf. Otak kiri ini mempunyai tugas untuk regulasi sebagian tindakan yang dilakukan oleh tubuh serta juga mengatur fungsi dari berbagai organ.( Parta Ibeng, 2020).

\section{B. Struktur Otak Kiri}

Struktuk otak kiri ini sangat kompleks, memiliki jutaan sel sistem saraf pada manusia serta neuron yang saling bekerja sama dalam melakukan tugasnya. Bentuknya ini separuh dari bagian otak besar yang berhubungan saling berhubungan pada syaraf serta juga jaringan di otak kanan. kita pasti tau bahwa pengertian jaringan saraf ini berhubungan dengan bagian penting dari organ tubuh lainnya. Apabila memiliki otak kiri yang sehat, tentu hal tersebut akan mendorong kesehatan serta memaksimalkan fungsi dalam berfikir.

Antara neuron satu dengan yang lain itu saling terikat, sehingga akan terlihat seperti rantai yang tidak pernah terputus. Neuron yang satu itu membawa informasi ke neuron lainnya serta juga membawa bahan kimia yang yang disebut dengan neurotransmitter. Ratusan juta neuron yang saling terkait di dalam struktur otak kiri itu yang bertugas di dalam membawa segala macam informasi ke otak. 


\section{Fungsi Otak Kiri}

Otak kiri ini mempunyai fungsi yang luas serta sakral dalam aktifitas manusia, tanpa otak kiri, manusia juga tidak akan mungkin untuk hidup serta berkembang. Berikut bermacam fungsinya:

\section{Pengontrolan}

Mengontrol tubuh bagian kiri, seluruh organ tubuh itu berada dalam kontrol otak kiri, Apabila terjadi kerusakan pada otak kiri tentu dampaknya ialah gangguan kesehatan seperti misalnya syaraf mati atau lumpuh pada tubuh bagian kiri.

\section{E. Keterampilan Angka Angka}

Otak kiri ini berperan di dalam segala materi atau bidang pembelajaran yang berhubungan dengan suatu perhitungan. Otak kiri ini mampu menganalisa dan menghitung dengan sangat matang, misalnya seperti dalam pembelajaran matematika, fisika, kimia, serta juga sains. Orang yang menguasai bidang tersebut ialah orang yang otak kirinya lebih dominan (lebih berperan).

\section{F. Sebagai Pengambil Tindakan yang Mengandalkan Logika dan Rasio}

Berperan di dalam membuat pertimbangan, di dalam memberi kekuatan serta tekad untuk disiplin, dan juga berfikir secara teknis serta penuh aturan. Otak kiri ini mempengaruhi pikiran bawah sadar manusia untuk berbuat serta melakukan sesuatu dengan secara sistematis dengan mengandalkan logika serta rasio.

\section{G. Pusat Inteligent Quotient (IQ)}

Pusat IQ ini merupakan pusat kecerdasan yang mencakup sifat pikiran yang berhubungan dengan kemampuan menalar, merencanakan, memecahkan masalah, berfikir abstrak, serta memahami bahasa. Hal tersebut berkaitan erat dengan kemampuan kognitif masing-masing individu. 


\section{H. Obyektifitas}

Orang yang lebih dominan dalam menggunakan otak kiri ini umumnya memilih alasan untuk segala sesuatu yang lain itu dengan menggunakan logika rasional di dalam mengidentifikasi penyebab masalah serta kemudian berfikir cara mengatasinya, intinya orang itu ialah orang yang detail oriented.

\section{Menulis dan Membaca}

Kemampuan dalam menulis serta membaca ini juga merupakan suatu kegiatan atau aktivitas yang memerlukan pemikiran serta konsentrasi untuk menyusun dan juga memahami berbagai kata yang nantinya akan terekam di dalam ingatan serta menjadi bahan untuk berfikir selanjutnya dengan secara logis sesuai ilmu atau pandangan yang didapat sebelumnya. Membaca serta menulis ini merupakan kecerdasan yang ditanamkan sejak kecil yang nantinya akan mengalami perkembangan itu sesuai kemampuan dari tiap tiap individu. Kemampuan itu dipengaruhi serta dijalankan fungsinya oleh otak kiri.

\section{J. Cara Kerja Otak Kiri}

Kamu tentu berfikir, bagaimana serta seperti apa otak kiri ini bekerja sehingga mampu menghasilkan kecerdasan yang luar biasa dan juga berbeda beda pada tiap orang. Adapun cara kerja dari otak kiri ini ialah dengan menggunakan daya ingat yang memiliki sifat jangka pendek (short term memory) sehingga akan berpengaruh pada fungsi berbicara, berbahasa, serta matematika. Jutaan sel sel di dalam otak kiri ini mampu memproses informasi yang memiliki sifat logis, lineal, serta rasional.

Otak kiri ini bekerja dengan memproses dunia dengan berdasarkan realitas yang menghasilkan penafsiran abstrak serta simbolis sehingga menjurus pada kemampuan di dalam melakukan tugas tugas itu dengan secara teratur dengan detail dan fakta. 
Demikianlah penjelasan mengenai Pengertian Otak Kiri, Struktur, Fungsi dan Cara Kerjanya, semoga apa yang diuraikan dapat bermanfaat untuk teman-teman semua, terima kasih. 


\section{BAB 02 \\ BERPIKIR DENGAN OTAK KIRI}

\section{A. Otak Kiri}

Picture1Dilansir dari perbedaan otak kanan dengan otak kiri pertama kali disampaikan oleh Roger Sperry (1913-1994) yang merupakan seorang neuropsikologi. Otak kiri manusia pada umumnya mendominasi bahasa, logika, angka; bahkan jika kita ingin mengungkapkan sebuah fakta, otak kiri akan menariknya dari memori kita.Ternyata, otak kiri dan kanan memiliki kemampuan yang bisa di pergunakan sehingga bisa membantu satu sama lain. Untuk kalian yang memiliki dominasi otak kiri, berikut adalah metode pembelajaran yang baik untuk kalian:

\section{B. Belajar dengan Menggunakan Angka}

Picture4 Untuk kalian yang di dominasi otak kiri, maka sebaiknya kalian memilih jurusan yang memiliki mata kuliah yang menggunakan angka, seperti matematika, fisika, pembukuan, dll. Orang yang di dominasi otak kiri akan lebih mudah dalam berhadapan dengan angka. Dengan menggunakan angka, mereka bisa menemukan cara tersendiri untuk bisa menghitung bahkan bisa menggunakan metode mental aritmatika yaitu merupakan salah satu metode dengan menggunakan alat hitung apapun dengan cara membayangkannya, sehingga mereka tidak membutuhkan kertas sebagai alat bantu untuk meghitung tetapi perhitungan mereka sudah ada di dalam kepala.

\section{Belajar Bahasa}

Picture2Dominasi otak kiri lainnya adalah kemampuan bahasa. Oleh karena itu, orang yang di dominasi otak kiri akan lebih mudah belajar bahasa. Metode yang digunakan bisa bervariasi dari mulai mendengarkan musik, menonton film, 
dll. Sehingga daya serap terhadap pembelajaran bahasa asing lebih tinggi.

\section{Logika dengan Teka-Teki}

Picture3 Logika merupakan salah satu yang di dominasi oleh otak kiri. Beberapa contoh yang dapat dilakukan untuk melatih logika adalah dengan membaca komik, buku, atau sumber bacaan lainnya yang berkaitan dengan teka-teki. Dengan membaca teka-teki, maka logika akan terus di latih di dalam otak kiri. Bahan bacaannya misalnya sherlock holmes yang bisa membantu seseorang melatih kemampuan logika dan daya ingatnya.

\section{E. Membedakan Berfikir dengan Otak Kanan dan Kiri}

Otak merupakan bagian organ tubuh manusia yang menjadi segala daya kekuatan untuk hidup dan merespon segala stimulus dari luar. Otak manusia terbagi dalam 2 bagian, sebelah kiri dan sebelah kanan. Masing-masing bagian otak manusia memiliki tanggung jawab dalam proses berfikir, mempunyai spesialisasi kemampuan-kemampuan tertentu, meski tetap ada persilangan kemampuan antar kedua belahan otak.

Percobaan telah menunjukkan bahwa kedua sisi otak yang berbeda berperan untuk perilaku berpikir yang berbeda pula.

\section{Otak Kiri:}

Mengontrol tubuh bagian Kiri

Ketrampilan angka-angka

Matematika/ketrampilan ilmiah

Menganalisa

Obyektifitas

Menulis

Berbicara

Logika

Pertimbangan

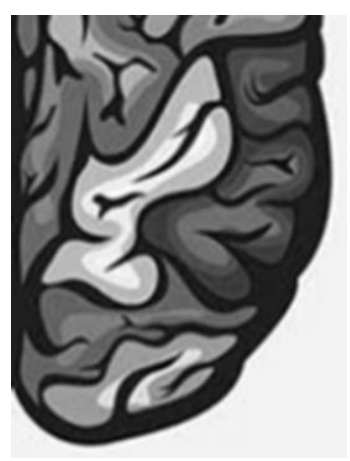


Menurut teori ini, otak kanan bertanggung jawab secara acak, intuitif, holistik, menyatukan dan pemikiran subyektif. Sementara otak kiri berperan untuk berfikir logika, skuensial, rasional, analitis, dan obyektif. Kebanyakan individu memiliki preferensi berbeda dalam menggunakan salah satu gaya berfikir ini. Jadi seseorang mungkin lebih cenderung menggunakan otak kiri, dan yang lain mungkin lebih cenderung ke otak kanan didasarkan pada bagaimana mereka menggunakan otak kanan dan otak kiri untuk memecahkan masalah.

1. Menggunakan Otak Kiri

Orang yang lebih dominan menggunakan otak kiri lebih memilih alasan untuk segala sesuatu yang lain. Mereka menggunakan logika rasional untuk mengidentifikasi penyebab masalah, dan kemudian berpikir tentang bagaimana cara mengatasinya. Pada intinya, orang yang berfikir menggunakan otak kiri adalah detail-oriented.

2. Identifikasi

Perbedaan antara fungsi otak kanan dan otak kiri pertama kali dibuat sebagai upaya awal untuk mengidentifikasi penyebab masalah berbicara. Hasil otopsi dari pasien yang mengalami gangguan berbicara yang parah menunjukkan adanya tumor besar di sisi otak kiri. Tumor ini menyebabkan pasien kehilangan kemampuan berfikir secara logis, meskipun tetap memiliki kemampuan untuk berbicara. Penelitian lebih lanjut mengungkapkan korelasi yang mendalam antara daerah aktivitas otak dan jenis tugas spesifik. Daerah penelitian sudah cukup berkembang, karena melakukan langkah rehabilitasi dan pengobatan cedera otak menjadi lebih penting.

3. Seimbang

Kebanyakan individu memiliki preferensi yang berbeda untuk salah satu gaya berpikir ini. Namun walau bagaimanapun, adalah lebih utuh jika sama-sama mahir berfikir menggunakan kedua cara berfikir tersebut. 
a. Kurikulum: Agar lebih utuh dalam menggunakan otak pada orientasi individu, pendidikan harus memberikan bobot yang sama dengan mengajarkan seni, kreativitas, dan keterampilan imajinasi.

b. Instruksi: Untuk menumbuhkan lebih banyak pengalaman skolastik pada kedua sisi otak, pendidik harus menggunakan teknik instruksi yang terkait dengan preferensi kedua sisi otak. Kelas di sekolah bisa meningkatkan kegiatan belajar otak kanan dengan mengikutkan lebih banyak pola, metafora, analogi, bermain peran, visual dan gerakan membaca, perhitungan, dan kegiatan analitis.

c. Penilaian: Untuk evaluasi yang lebih akurat, pendidik harus mengembangkan bentuk-bentuk penilaian baru yang mengembangkan bakat dan keterampilan dengan menggunakan rotak kanan.

Yuk Pahami Cara Kerja Otak Kiri dan Otak Kanan Agar Belajar Makin Maksimal! 